\title{
LA RELEVANCIA DE LA MISMIDAD EN EL ANÁLISIS DEL SER-PARA(VUELTO-A)-LA- MUERTE Y EL SER-TOTAL EN SER Y TIEMPO
}

\section{THE IMPORTANCE OF DASEIN'S SELFHOOD IN THE ANALYSIS OF BEING-TOWARD-DEATH AND BEING-A-WHOLE IN BEING AND TIME}

\author{
Juan José GARRIDO PERIÑÁN* \\ Universidad de Sevilla
}

Resumen: El artículo de investigación pretende lograr una articulación y tematización de dos fenómenos y/o existenciarios eminentes en el libro de Heidegger Ser y Tiempo (\$\$ 45-53): ser-para(vuelto-a)-la-muerte y ser-total, ambos relativos al Dasein, a fin de mostrar que el fenómeno denominado mismidad del Dasein es una condición necesaria y suficiente en aras, precisamente, de lograr una captación fenomenológica plena sobre tales existenciarios.

Palabras ClaVe: Mismidad; Ser-para(vuelto-a)-la-muerte; Ser-total; Fenomenología.

\footnotetext{
* Profesor Ayudante Doctor, Departamento de Estética e Historia de la Filosofía, Calle Camilo José Cela S/N, 41018, Sevilla. Este trabajo se ha realizado bajo la cobertura del siguiente Proyecto I+D De Excelencia: "Dinámicas del cuidado y lo inquietante. Figuras de lo inquietante en el debate fenomenológico contemporáneo y las posibilidades de una orientación filosófica. Configuración teórica y metodológica" (FFI2017/83770-P), financiado por el Ministerio de Innovación, Ciencias y Universidades del Reino de Espańa.
} 
Aвstract: This research paper aims to achieve an articulation and thematization of two eminent Phenomena and/or Existentialia in Heidegger's Book Being and Time ( $\$ \$ 45-53)$ : Being-Toward-Death and Being-a-Whole, both of which relate to Dasein, in order to show that the phenomenon called Dasein's Selfhood is a necessary and sufficient condition to achieve a full phenomenological apprehension of these Existentalia.

KeYwords: Selfhood, Being-Toward-Death, Being-a-Whole; Phenomenology.

\section{Introducción}

El presente artículo de investigación, que se ejercerá sobre los $\$ \$ 45-53$ de Sein und Zeit ${ }^{1}$, además de realizar un análisis fenomenológico de orientación metódica y temática sobre los fenómenos relativos al "ser-para(vuelto-a)la-muerte" [Sein-zum-Tode] y el "ser-total" [Ganzsein], intentará mostrar que, a fin de lograr una captación fenomenológica completa y genuina de este enteDasein, es necesario la exploración, articulación y tematización del fenómeno "mismidad"2 [Selbstheit]. Esta mismidad, que ha sido ya abierta y estudiada en anteriores artículos de investigación con especial atención en la I Sección de SuZ (Garrido-Perińán, 2019a: 175-200, 2019b: 887-911 y 2019c: 159-175), va a ser entendida como un fenómeno ligado al "estado de apertura" [Erschlossenheit] del Dasein, en tanto correlato existencial que sitúa a este ente ante una posibilidad eminente por cuanto, en términos aleteilógicos ${ }^{3}$, los rendimientos de tal apertura señalan al cumplimiento de una posibilidad por la que el Dasein puede ser "lo

${ }^{1}$ Como la siguiente obra de Heidegger va a emplearse con demasiada asiduidad en el artículo de investigación, proponemos el uso de la siguiente abreviatura $\operatorname{SuZ}$ (2002) de cara a facilitar su citación. Todas las traducciones de la obra de Heidegger son responsabilidad del autor. 2 Tomado de modo muy provisorio, el sí-mismo, o la mismidad, apunta a un fenómeno temporal en las dimensiones prácticas del "mundo entorno" [Um-welt], "mundo compartido" [Mit-welt] y, por último, "mundo de sí mismo" [Selbst-welt] (Cf. Heidegger, 2006: 176; 1995: $11,13,103,187-188,192,204,211,212-214,227-228,228,232$, 237-241, 245-247, $253-$ $255,298,331-332,1992: 54-58,54-58,342,348,440-441,442 ; 1988: 29$ y $102 ; 1976$ : 236, 338-344, 344-347 y 1975: 194, 224-228, 242, 249, 394-395 422, 425).

3 Nos valemos del término empleado por A. Vigo, quien a su vez lo toma de H.-G. Gadamer (1993: 177 ss.). Para A. Vigo (2014: 129-158), la aleteiología es un intento por reubicar la temática de la verdad, entendida como aletheia, dentro de lo que, por la tradición, se denominó "verdad trascendental", esto es, como la apertura posibilitadora de la comprensión del ente en su ser. 
que es", o sea: lograr una posibilidad fáctica que tenga por fin la "transparencia" [Durchsichtigkeit] (Cf. SuZ:146) de su propio e irresoluble modo de ser. Se comprenderá, entonces, que la mismidad es un fenómeno eminente para lograr no solo las tareas arribas mentadas, sino para, en último término, dar cuenta del fenómeno de la "propiedad" [Eigentlichkeit] de la existencia.

\section{Ser-para(vuelto-a)-la-muerte y ser-total}

La apuesta filosófica de Heidegger, al menos hasta $S u Z$, radica en situar la pregunta sobre el ser como horizonte trascendental que soporta la comprensión del ente en general, a través de los rendimientos fenomenológicos-hermenéuticos ejercidos en la llamada Analítica-Existencial, de tal manera que, podría decirse, la pregunta por el ser constituye el correlato fenomenológico de la pregunta por el Dasein, y esto, en cambio, sin confundir los ámbitos temáticos a los que refieren ambos fenómenos 5 . De suerte que en la II Sección, una vez realizado el trabajo de campo por dilucidar la situación hermenéutica, de lo que se trata es de ejecutar un análisis fenomenológico que atienda a la posibilidad de aprehender al Dasein de una manera originaria, esto es, desde su particular "originariedad" [Ursprünglichkeit] (Heidegger, 2015: 97; 2013: 505 y 591; SuZ: 231; 1989: 500; 1983: 8; 1981: 92 y 132). Que sea originaria la elucidación sobre el ser del Dasein significa que tal elucidación tiene la capacidad de retrotraer y proyectar el fenómeno eminente del este ente a una mostración de carácter totalizante, atendiendo a

\footnotetext{
${ }^{4}$ El existenciario "transparencia" tiene un importante rol en la cuestión estudiada, pues, a partir de él se establece la modalidad existencial denominada "propiedad" [Eigentlichkeit]. La "transparencia" es, entonces, una modalidad peculiar de "autoconocimiento" [Selbsterkenntnis], de naturaleza ejecutiva-comprensiva, por la que el Dasein puede llegar a atisbarse desde su total integridad, articulando, como un todo global y holístico, todo los momentos estructurales a su constitución existencial, o sea, desde los correlatos relativos al ser-en-el-mundo: "mundo-entorno" [Um-welt], "mundo-compartido" [Mit-welt $]$ y "mundo de sí-mismo" [Selbst-welt].

5 Hay que tener muy en claro que la meta del tratado era la elaboración de un horizonte temporal, re-obtenido por mor de una hermenéutica de la "temporalidad" [Zeitlichkeit] mundana del Dasein, que sirviera como un "trascendental" desde donde comprender el ser del ente en general, en tanto temporalidad [Temporalität]. Este horizonte trascendental y temporal iba a ser expuesto en la III Sección, que no ha sido publicada jamás, por mucho que se considere el curso del Semestre de verano de 1927 su continuación (Cf. Heidegger 1975).
} 
cada una de sus estructuras intencionales en cuanto "ser-en-el-mundo". Esto conlleva aceptar unas exigencias de carácter metódico y temático, a saber: la primera exigencia tiene que ver con la posibilidad de retrotraer el fenómeno esquivo del Dasein a su "haber-previo" [Vor-habe], es decir, con la posibilidad de lograr un "ver-previo" [Vor-sicht] que pueda "pre-concebir" [Vor-griff] (SuZ: 151 ss.) la irrepetible situación hermenéutica, donde no solo se ubican y consolidan los presupuestos, culturales e históricos que rodean al Dasein, sino el propio horizonte insondable al que remite la pre-comprensión, en tanto fenómeno fundante, el cual soporta cualquier acto relativo a la comprensión particular y concreta de cada fenómeno. Según esta tentativa, de lo que se trata es de remitir la referida comprensión, que el Dasein porta sobre su ser, hacia el elemento contextual de la pre-comprensión, y esto, además, de un modo singular, ya que tal retrotraer al ámbito originario de la pre-comprensión, se ha de realizar respetando el carácter unitario que ya se ha fraguado y "atestiguado" [bezengen], aunque sea de modo tácito y desfigurado, en el fenómeno del "cuidado" [Sorge] (SuZ: 191-197). El haber-previo, proyectado como posibilidad aprehensora por parte del Dasein de su situación hermenéutica, tiene que ser, por ende, captado en su momento unitario $^{6}$. Esta exigencia de unidad, a modo de segunda exigencia, nos lleva a plantear el esclarecimiento fenomenológico de la modalidad llamada "propiedad" [Eigentlichkeit], en tanto colofón al que debe apuntar el análisis existencial de corte ontológico, siendo que ha de entreverse una vinculación entre unidad y propiedad. Tal nexo no es claro ni explicitado con demora por el mismo Heidegger. Desde nuestra interpretación, la vinculación entre unidad y propiedad del existir tiene que ser buscada en el rol que juega la noción de "sentido de ejecución"7 [Vollzugssinn]. Grosso modo, Heidegger piensa que la captación unitaria, ya entrevista en el momento del cuidado, es una forma ejecutiva de existir, una "manera de existir" [Weisen zu existieren], un "cómo" [Wie], siendo que la

\footnotetext{
${ }^{6}$ Por esta razón, debido a las exigencias de unidad, el cuidado va a desvelar la "temporalidad" [Zeitlichkeit] como eminente horizonte por donde se ejerce todo acto de pre-comprensión, primero, y de comprensión, después.

7 Heidegger, desde sus primeros cursos friburgueses, propone que las posibilidades de acceso al fenómeno estén marcadas bajo 3 sentidos: "sentido se contenido" [Gehaltsinn], "sentido de relación" [Bezugssinn] y "sentido de ejecución” [Vollzugssinn], siendo el sentido de contenido subsidiario del sentido relacional, esto es, de la forma en la que la existencia es vivida, bajo sus referencias y situaciones concretas y fácticas. El sentido de ejecución es importante aquí porque no hay ningún sentido relacional que no conlleve, desde sí mismo, una ejecución, una praxis, un hacer. Los contenidos que, como indicadores formales, expresa la hermenéutica de la facticidad, deben ser, en "cada caso" [Jeweiligkeit], ejecutados, llevados a la praxis. Esta división, en la manera de entender el fenómeno, no es nueva de $S u Z$, sino que ya fue tematizada, al menos implícitamente en algunos cursos docentes anteriores (1979).
} 
captación comporta intrínsecamente la necesidad de ejecución, entendida como un llevar a cabo el "poder-ser" [Sein-können], que vertebra a la misma existencia en tanto existencia. Y esto, precisamente, porque la propiedad de la existencia es planteada por Heidegger en términos exclusivamente ejecutivos y cinéticos, como "contra-movimiento" [Gegenbewegung] del momento fáctico de existir en la "cotidianidad del término medio" [durchschnittliche Alltäglichkeit], característico de la llamada "refracción ontológica" [ontologische Rückstrahlung] (SuZ: 15-16), cuyo último sentido es ganar la posibilidad, hermenéutico-ejecutiva, de un poder-ser en concordancia con el genuino carácter del Dasein, ya intuido en los existenciarios: "tener-que-ser" [zu-sein] y "ser-en-cada-caso-mío" [Jemeinigkeit] (SuZ: 41-43). Esta materialización de la propiedad de la existencia, conforme a sus características formales, tiene como último objetivo asentar el existenciario total del cuidado no como reflejo del término medio, sino ante una posibilidad atestiguada en la experiencia, en propiedad, de carácter ontológico -vale decir: no óntico-, o sea, como una posibilidad ligada inexcusablemente a la temporalidad finita del Dasein y, por tanto, constituyéndolo -ahora de verdad-como el gran existenciario que recoge la totalidad estructural del ser del Dasein en tanto temporalidad.

¿De dónde vienen, entonces, estas exigencias hacia la captación total e íntegra sobre el ser del Dasein, si este mismo ente es, existe, en el modo de lo incompleto e imperfecto, en un modo de existencia truncada?

\subsection{La relevancia del ser-para(vuelto-a-)-la-muerte}

Desde que Heidegger esbozará la "no-extrañeza" [ nicht-Fremdheit] del Dasein con respecto a su ser, el análisis existencial se ha desarrollado en tres niveles, a saber: primero, en el nivel óntico, donde se ejerce el dominio de la comprensión pública, aquello que, desde la fenomenología, podríamos denominar actitud natural; segundo, un nivel pre-ontológico, en tanto horizonte o "haber-previo",

\footnotetext{
${ }^{8}$ No es muy explícito Heidegger al respecto, aunque en $S u Z$ ya habla de esta cercanía, lejanía y no extrañeza en estos términos (43): "Lo ónticamente más cercano y conocido es lo ontológicamente más lejano, desconocido y constantemente pasado por alto en su significación ontológica". [Das ontisch Nächste und Bekannte ist das ontologisch Fernste, Unerkannte und in seiner ontologischen Bedeutung ständig Übersehene]. También, algo antes (16), Heidegger explicita que, aparte de ser el "más lejano" [am fernsten] y el "más cercano" [am nächsten], el ser del Dasein, su sentido, es "no-extraño" [nicht fremd].
} 
donde acontece la experiencia de corte pre-reflexivo y/o pre-comprensivo (también llamado nivel hermenéutico); tercero, desde un nivel ontológico, entendido como la manera de llevar a término expreso y temático lo recogido, sentido y pensado ya, en la experiencia pre-reflexiva o "pre-teorética" [Vortheoretische]. En virtud de tal consideración, la propiedad del existir, como fenómeno eminente con respecto al Dasein y en relación con el análisis fenomenológico, tiene, de alguna manera, que quedar tácitamente dada y/o "experienciada" en la vivencia pre-comprensiva que el Dasein, en calidad de ente señalado por la comprensión del ser (com)porta. De otro modo: el Dasein, existiendo en el mundo, ha de tener un acceso pre-comprensivo con respecto a sí en tanto totalidad, pues de lo contrario, el análisis fenomenológico no pudiera ser tal, debido a la razón de que no hubiera posibilidad de acreditar, vía experiencia/vivencia, aquello que, en cada caso, es tematizado. En esta situación, el "posible ser total" [das mögliche Ganzsein] del Dasein, aunque de modo nivelado y auto-delegatorio, tiene que constituir cierta experiencia. El problema, el cual hace aún más esquivo la empresa de su elucidación, radica en la tendencia del Dasein mismo para con su ser a no atender a eso que, de algún modo u otro, se ha "experienciado" bajo el rótulo del posible ser-total. Esta estructura intencional, de huida y de completo no querer ver, fue ya abierta en el análisis del "miedo" [Furcht] (SuZ: 140-142), experiencia mediante la cual el Dasein se comprende como reflejo del mundo en el que habita, como correlato cadente, normalmente caído, de su mundo. De algún modo, ante esta tesitura, mediante la cual el Dasein pudiera dar cuenta de la posibilidad ontológica de su existencia, en el modo de la propiedad, sucede algo análogo: la experiencia relativa al acceso pre-comprensivo de la totalidad de este ente, para con su ser, se ejerce análogamente a una movilidad, de carácter intencional y hermenéutico, cuyo resultado es, justamente, no querer atender, mirar y comprender aquello visto y vivenciado por el posible ser-total de este ente $^{9}$, de tal manera que el tipo de carácter propio del conocimiento ontológico se presenta siempre ya de modo indirecto y oblicuo, en continua fricción con formas de disimulo y desfiguración.

Una vez precisado la complejidad en el modo de presentación de lo ontológico, el siguiente paso casi parece obvio y natural: el "ser-para(vuelto-a)-la-muerte"10

\footnotetext{
${ }^{9}$ Lo tematizado, mediante el análisis existencial, no son "propiedades" [Eigenschaften] relativas a objetos, sino modos de ser o existir, posibilidades en completa conexión con el ser del Dasein.

${ }^{10}$ Debido a la complejidad temática y a causa de que tal expresión va a ser de uso reiterado en el artículo de investigación, a veces, para hacer mención de tal existenciario, se empleará nociones de carácter similar, las cuales podrían conllevar multiplicidad semántica con el con-
} 
es la posibilidad según la cual cada Dasein puede atender a su posible ser-total, ya que, a través del morir, nuestro ser queda como englobado y articulado en sus límites intrínsecos y singulares. Ahora bien, el existenciario sobre la muerte no significa que el Dasein vive muriendo, o que su ser está, en exclusividad, condenado a morir, a la manera en la que ha sido entendido por ciertos filósofos (Arendt, 1998: 175 ss.; Lütkehaus, 2006). El ser-para(vuelto-a)-la-muerte, como todo existenciario, es una figura relativa al comportarse del Dasein, en tanto modalidad intencional, la cual hace referencia a un especial tipo de relación de este Dasein con su genuino poder-ser, siendo, entonces, que lo que abre el existenciario sobre la muerte no es solo el hecho bruto de que nos vamos a morir, sino el hecho fáctico-comprensivo de que, mientras existimos, nuestro ser se comporta siempre ya, proyectado, con la posibilidad de dejar de ser, prototípica y en homologación con su poder-ser (SuZ: 234). Tal es así que el ser-para(vuelto-a)-la-muerte es un modo de comportarse del Dasein con respecto a su propio "fin(al)" [Ende], y no un hecho factual más, por tal razón este existenciario puede ser ejecutado bajo las modalidades de la impropiedad y/o propiedad. Esto último, por lo demás, demuestra la imposibilidad de aprehender fenomenológicamente la muerte según el modelo respectivo de la Vorhandenheit, a la manera de la cosa o el "objeto"11 [Gegenstand]. Ahora bien, los existenciarios "ser-para(vuelto-a)-lamuerte" y el "ser-total" no son lo mismo y tampoco manifiestan el mismo ámbito de posibilidad: no hay posibilidad de materializar la totalidad del ser del Dasein

\footnotetext{
sabido peligro de que la definición temática quede determinada de modo ambiguo. Expresiones tales como "fenomenología del morir", "el morir", la "muerte relativa al Dasein", etc., la mayoría de las veces, se insertan como sinónimos de la experiencia fenomenológica denominada "ser-para(vuelto-a)-la-muerte". En virtud del desarrollo ulterior, el lector podrá comprender porqué nociones tales como "muerte" y "ser-para(vuelto-a)-la-muerte" son dispares y no han de ser homologadas.

11 Gegenstand es unas de las traducciones al español de objeto, que puede ser traducido, del mismo modo, por Objekt. Desde diferentes perspectivas, hay quienes sostienen su tajante división (Caygill, 2000: 317), considerándola importantísima para la matriz filosófica de la filosofía trascendental kantiana, siendo Gegenstände objetos de la experiencia en su sentido lato, mientras que Objekt es el objeto de la experiencia en un sentido restringido, o sea, como objeto relativo al entendimiento. Ahora bien, hay controversia, Pedro Ribas, uno de los traductores al español de $K r V$ (Kant, 2005: XXV), según parece, desestima la diferenciación, al pensarla de poco importante; también lo hacen Förster y Rosen (Kant, 1993:49), traductores al inglés del Opus Postumum kantiano. Heidegger, a mi parecer, a lo largo de su interpretación, mantiene tal división, entendida en términos ontológicos, en virtud, precisamente, del aporte que lo trascendental tendría sobre la misma experiencia, haciéndola depender de criterios logicistas, es decir, pensado el objeto como Objekt, o correlato lógico de la unidad de apercepción, en presunto divorcio con la intuición sensible, a la que estaría, irremediablemente, emparentada la noción germana Gegenstand. Como resulta conocido, Heidegger es muy crítico con esta interpretación.
} 
si antes no se constata, en tanto comportarse, el ser-para(vuelto-a)-la-muerte, de tal forma que, entre ellos, hay una relación dispareja, pues el ser-para(vuelto-a)-la muerte es el que soporta la experiencia posible de la totalidad, no al revés. Si el serpara(vuelto-a)-la-muerte provee la referencia mediante la cual puede la totalidad realmente darse, y constituir una experiencia con pleno derecho en la existencia del Dasein, esto significa que la totalidad mienta la posibilidad de demarcación y determinación de este modo de ser del Dasein, si y solo si, en tanto ser-posible, o sea, como "falta" [Ausstand] (SuZ: 236), y mientras el Dasein es, este ente no es (existe) de modo completo, esto es, que existe en el modo del "todavía-no" [Noch-nicht].

Bajo este último descubrimiento sobre la falta es comprensible situar y anexar el carácter incompleto, relativo al modo de ser del Dasein, con su exigencia de totalidad, es decir, es posible cohesionar la posibilidad de que un ser incompleto pueda reclamar para sí una totalización de su ser, a la manera del ser-posible, tal y como es ejercido por Heidegger con verdadero denuedo.

\subsection{La posibilidad ontológica-existencial}

La pregunta por la totalidad del Dasein fue transida desde una semántica relativa al modo de ser del ente intramundano, o sea: la perteneciente al modo de ser "ante los ojos" [vorhanden]. Por esta razón, Heidegger quiere, de nuevo, preguntar por los existenciarios que delimitan los contornos de tal pregunta por la totalidad, totalidad ya presentida en el descubrimiento del "cuidado" [Sorge]. La tarea estribaba, entonces, en alcanzar una restitución, digamos, ontológicoexistencial por sobre los momentos que, cual figura, componen la hechura del cuidado, por un lado ${ }^{12}$, y la "totalidad" [Ganzheit], por otro: "el todavía-no-ser" [das Noch-nicht-sein], "el anticiparse" [das Vorweg], y "el fin(al)" [das Ende]. Precisamente, a fin de hacerse cargo de esta totalidad existencial, de lo que se trata es que el Dasein sea capaz de obtener una elucidación, desde una radicalidad metódica proveniente de la fenomenología, del modo como su ser se relaciona con su fin(al). Es aquí donde se inserta el análisis del ser-para(vuelto-a)-la-muerte. Asimismo, este ser-para(vuelto-a)-la-muerte va a constituir la posibilidad, por

12 He aquí la importancia estructural del cuidado (SuZ: 252): "El cuidado es el título ontológico para la totalidad del todo estructural del Dasein" [Sorge ist der ontologische Titel für die Ganzheit des Strukturganzen des Daseins]. 
la cual el Dasein puede hacerse cargo de lo que es, en el modo de su específica unidad y/o totalidad existencial, tomándose a sí-mismo como una posibilidad escindida en el cuidado y, por tanto, vertebrando cualquier "modalización" de ejecución de la respectiva existencia ${ }^{13}$.

Por otro lado, el señalamiento óptimo del fenómeno del morir sobre el ser del Dasein tiene que ver con una permeabilidad que la misma "muerte" posee con respecto al Dasein, pues, de algún modo su relación con el fin(al), coloca a este ente ante un saber constituido específicamente como nuda posibilidad. En efecto, sabiéndonos mortales -pues vemos que los demás "fenecen" [verenden]tenemos una primera, aunque ruda, constatación de que, nolen volens, vamos a morir, siendo la muerte una posibilidad ineludible para nosotros. En este sentido, la muerte es un hecho no consumado y, por ende, posible ¿Está barajando Heidegger, al menos, dos nociones diferentes de posibilidad? Pensamos que sí. En esta primera definición, que hace referencia a la relación que tenemos con el morir como un hecho todavía-no consumado pero ineludible, se esboza una posibilidad que se constituye al modo relativamente "categorial", pudiéndose entender, esta misma posibilidad, casi en términos clásicos: la muerte es el acto, la vida, la potencia. La segunda tentativa de definición de la posibilidad, en cambio, podríamos llamarla posibilidad ontológica y/o existencial, la cual queda definida como una relación en estrecho vínculo con el modo de ser del Dasein, o sea, se constituye como una posibilidad de corte comprensivo-ejecutivo por la cual este ente logra una comprensión genuina y transparente de su ser.

Por último, el ser-para(vuelto-a)-la-muerte, entendido como una relación comprensiva y óptima, en tanto constituida como posibilidad, para el desvelamiento del modo de ser del Dasein, no ha de significar algo así como que tal ente existe muriendo (Edwards, 1979: 16, 26 y 60). Lo importante es que el Dasein, en tanto poder-ser, y de un modo fundante, existe desde y con posibilidades en relación con su propio ser. La relación con la muerte, pero también la relación con el nacimiento son modos de cristalización de esta posibilidad ontológica. De ahí que Heidegger diga que el Dasein "existe como nacido" [existiert gebürtig] y, a la par, "muere como nacido" [gebürtig stirbt] (SuZ: 374). El porqué la muerte tiene preeminencia sobre el nacimiento puede ser sobreentendido, por cuanto, desde el ser-para(vuelto-a)-la-muerte, se constituye tentativamente una posibilidad de aprehensión y testimonio de la totalidad de este ente señalado.

13 Las modalizaciones ejecutivas-comprensivas se ejercen como correlatos de su constitución como "ser-en-el-mundo" [in-der-Welt-sein]. 


\section{Ser-para(vuelto-a)-la-muerte: una naciente mismidad}

El tratamiento fenomenológico del morir tiene, en primer lugar, que esclarecer y tematizar el modo relacional, vale decir: el comportarse singularmente especifico de este Dasein con su fin(al), para, en su segundo momento, ganar una comprensión explícita y apropiadora, con cierto carácter de unidad, de la totalidad de este ente.

Toca, pues, ejercer un análisis del ser-para-(vuelto-a)-la-muerte en tanto vía de alcance para que el Dasein tenga un acceso íntegro y total para con su ser. Esta será una condición necesaria a fin de poder pensar la mismidad.

\subsection{La irrupción del ser-en-cada-caso-mío}

Ahora bien, a pesar del trágico tono que la pregunta sobre la muerte posee, no hay que olvidar que ésta se desarrolla al socaire de un ejercicio fenomenológico despierto cuya finalidad es hacer explícito y temático las condiciones de posibilidad de la muerte, en tanto hecho que atañe al Dasein, con vistas a poner al descubierto, por así decir, la posibilidad integral de su ser. La atenencia fenomenológica obliga, entonces, a partir del modo cotidiano de tener experiencia sobre la muerte ¿Cuál sería tal experiencia? Heidegger cree atisbarla bajo la experiencia de la muerte de los otros, aquellos existentes como nosotros. La muerte de los otros, en opinión de Heidegger, no puede servir de punto de partida a fin de obtener una comprensión existencial y ontológica, es decir en propiedad, del fenómeno de la muerte. Una pregunta importante, pues, sale a relucir: ¿cómo, entonces, sería posible un análisis fenomenológico del morir, si no hubiera posibilidad de su experiencia? Que, de algún modo, la fundamentación del análisis fenomenológico, basado en la muerte de los otros, desvirtúe y desfigure una genuina y ontológica manera de comprender la muerte, como fenómeno eminente de cara a la elucidación de la totalidad del ser del Dasein, no ha de significar su necesaria "hipostatización" cuando, por ventura, se intenta llevar a cabo un análisis ontológico-existencial de tal fenómeno, sino que, antes bien, la muerte de los otros representa el único camino por el cual es posible el desarrollo temático de la muerte como eminente posibilidad del Dasein. Por tanto, hay que atender cuidadosamente a lo implícito en las consideraciones que creen explicar el fenómeno de la muerte al amparo de la mediación de la muerte de los otros. 
La respuesta negativa de Heidegger no es, empero, azarosa, aunque, prima facie, se pudiera comprender tal que así, sobre todo si se tiene en mente, cual prejuicio, lo muchas veces acusado, sobre el solipsismo que acarrea la angustia, la cual se la piensa como disposición afectiva del ser-para(vuelto-a)-la-muerte (SuZ: 184191). En nuestra opinión, consideraciones de tal calado son realmente parciales, por cuanto suelen olvidar el horizonte de sujeción metódico y temático en el que se realiza la ejecución fenomenológica de tal existenciario. Un olvido de estas características resulta nefando de cara a la elucidación integral y holística, por fenomenológica, del ser-para(vuelto-a)-la-muerte, ya que, sin estas atenencias y relaciones de carácter metódico y formal, el fenómeno de la muerte no va a poder ponerse en relación con la impronta existencial del Dasein, justo, y esencialmente, de lo que se trata aquí. Estas consecuencias metódicas deben buscarse sobre la definición del Dasein, que tiene su culmen en el desarrollo del $\$ 44$ cuando este ente es tematizado como una forma eminente de "estado de apertura/aperturidad" [Erschlossenheit] y ser-descubridor [Entdeckend-sein] (SuZ: 220-221). ¿Qué ha de significar esto? Para decirlo lo más brevemente posible: la muerte no puede consistir en la determinación de un hecho bruto, empírico, y ello en virtud del Dasein mismo, por la sencilla razón de que tal Dasein no es una entidad, una substancia de la cual pudieran predicarse características y propiedades, sino una modalidad intencional constituida como correlato del ser-en-el-mundo, sobre horizontes comprensivos fácticamente abiertos. Esto es lo que quiere decir, como muchas ocasiones se repite en la obra, que el Dasein es un "poder-ser" [Können-sein]. Poder-ser no significa tan solo que el Dasein existe, está siendo retro-proyectivamente desde sus posibilidades, sino que es, esencialmente, tales posibilidades ${ }^{14}$. Por tanto, el fenómeno de la muerte, el cual es pensando por Heidegger en tanto ser-para(vuelto-a)-la-muerte, debe constituirse no solo en (auto)referencia al Dasein, sino que solamente puede ser comprendido como "modalización" de una posibilidad perteneciente a este ente y en homologación con el carácter de apertura de su ser.

Pues bien, con la idea de seguir el análisis desplegado por Heidegger, éste, a la hora de poner al descubierto el modo de acceso implícito y correspondiente al fenómeno relativo a la muerte de los otros, habla de una "donación objetiva" [objektive Gegebenheit] (SuZ: 237), mediante la cual no solo el otro adquiere los caracteres objetivos, propios de la "objetualidad" [Gegenständlichkeit], cual correlato del estar-ahí [Vorhandenheit], sino que, peor aún, la muerte se constituye

${ }^{14}$ Aquí ya queda prefigurado la determinación existencial del Dasein basada en el "tener-queser" [zu-sein] y en el "ser-en-cada-caso-mío" [Jemeinigkeit]. 
como mera "finalización" [Beendigung]. Tal reducción se vería ejemplarmente plasmada en la constatación del cadáver como algo que ha dejado de vivir, bajo la modalidad de lo no-viviente y, por tanto, todavía regulado por el ideal de vida. ¿Significa esto que el difunto, sea familiar, querido o desconocido, deja de ser en idéntica forma, como cuando un útil, a saber, el bolígrafo se ve impedido como bolígrafo, roto o extraviado? ¿ No poseen los útiles, en cierta manera, el modo de específico de lo Vorhandenheit, a pesar de que remitan a una "totalidadrespeccional" [Bewandtnisganzheit] (Garrido-Periñán, 2019c:159-175)? Estas cuestiones deben ser respondidas de cara a dejar claro un aspecto específico y singular de la dimensión de los otros, mentada por Heidegger con anterioridad mediante el existenciario "ser-con" [Mit-sein] (SuZ: 117-125). La imposibilidad de definir al Dasein en términos sustanciales, y pensarlo, por tanto, como correlato cinético en el modo del ser-en-el-mundo, ha de significar, entre otras cosas, que los relatas, que constituyen las posibilidades efectivas relativas al modo de comportarse mismo del Dasein, poseen un carácter co-originario con respecto a este mismo ente, siendo que el Dasein no constituye el fundamento de relación para con lo relacionado, sus relatas, sino que es, siempre ya, lo que hace ${ }^{15}$. En términos efectivos, esto significa que los otros, como el Dasein mismo, aparecen ya bajo el modo de comprensión provista por los útiles, o sea, bajo el carácter del ente intramundano, desde la "ocupación práctica" [Besorgen] y en el circum abierto por el "mundo-entorno" [Um-welt]. Sin embargo, Heidegger reconoce un elemento refractario dentro del domino existencial de los otros, perteneciente a su estructura existencial fundamental del "ser-con" [Mit-sein], en relación con la capacidad de que éstos sean sustraídos y reglados bajo la modalidad perteneciente al ente intramundano. Por esta razón, dentro del análisis del ser-para(vueltoa)-la muerte, el cadáver tiene el carácter de "extinto" [Verstorbene], y el, por ejemplo, amigo que muere no es un hecho más, ni mucho menos homologable con la experiencia de pérdida o cancelación del útil ${ }^{16}$. En efecto, este carácter de análisis particular, ejercido sobre la muerte de los otros, tiene que ver con la relevancia que la "solicitud" [Fürsorge], como modalidad "posibilitante" de

\footnotetext{
15 (SuZ: 239): "Se es lo que se hace (practica)" [Man ist das, was man betreibt].

16 Aunque difieran en lo más esencial, Heidegger, con menos fricción, y Jaspers, con verdadero denuedo, enfatizan la relevancia de la muerte de los otros. En el caso de Jaspers, y al igual que Heidegger, piensa que es imposible, además de un error garrafal, que la muerte, entendida como hecho objetivo, pueda ser puesta en analogía con la experiencia límite ocasionada por el acontecimiento de la muerte de los otros, más y a sabiendas de que el fallecido es un amigo. En este sentido habla Jaspers de las "situaciones límites" [Grenzsituationen] (Jaspers, 1990: 259 ss.; 1932: 220 ss.; Lehmann, 1938) y establece, diríamos, una diferencia radical entre la muerte como situación límite y la muerte como hecho bruto y objetivo.
} 
cualquier tipo de relación interpersonal, tiene para el análisis de Heidegger. La solicitud, que prefigura la relevancia de la alteridad como un fenómeno fundante para el Dasein (Garrido-Periñán, 2019a: 175-200), no se ve abolida con el mero "fenecer" [Verenden], antes bien, sigue ejecutándose bajo la modalidad del seren-el-mundo proveniente de los enlutados. De esta manera, es posible explicar que, muriendo el amigo, los enlutados, que están en duelo, puedan llevarles flores a la tumba, comportarse con relación al fallecido, entre tanto porque lo que se experiencia, en este caso específico de la solicitud al modo de la honra [die ehrende Fürsorge], es un abandono y/o cancelación en el movimiento intencional proveniente del hecho de estar-uno-con-otros [Mitsein mit Anderen], en un "mundo compartido" ${ }^{17}$ [Mitwelt]. Lo relevante es aquí, a nuestro juicio, dilucidar si la experiencia de la muerte del conocido o el amigo, en su duelo y pérdida, es comparable con la manera en la que el Dasein tiene que relacionarse con su muerte, en el modo del ser-para(vuelto-a)-la-muerte. La respuesta de Heidegger es, de nuevo: no. ¿Por qué? La muerte de los otros no es precisamente la experiencia de (mi) morir, de nuestro dejar de ser en este mundo, sino que, a lo sumo, es un asistir a tal muerte (SuZ: 238), lo cual difiere del modo como el Dasein se relaciona y soporta su "tener-que-ser" [zu-sein] y su "llegar-al-fin" [als Zu-Endekommen]. Esta crítica hacia procedimientos derivados de cierta empatía para con la muerte de los otros son desechados por Heidegger en virtud de su capacidad por desvirtuar y desfigurar el correcto modo de acceso relativo al ser-para(vueltoa)-la-muerte. La premisa que sirve de base es que, por lo general, tales procedimientos se basan en hipótesis de partida, nada acreditables vía fenomenológica, siendo que el otro puede ser sustituido y reemplazado (SuZ: 239). Este horizonte de "re-emplazabilidad" [Vertretbarkeit] es una determinación que, con exclusividad, confunde el orden existencial con el respectivo del ente intramundano, y, además, desvirtúa la manera experiencial por la que el Dasein tiene que vivir su fin. De esta manera, el tratamiento, basado en la empatía como medio para saber de la muerte de los otros, además de errado en su acceso, es altamente nivelador y desfigurador con respecto al modo cómo el Dasein se relaciona con su muerte. Se entiende, entonces, que Heidegger, a fin de dejar sentenciada la problemática, se manifieste con aires tremebundos y afirme: "Nadie puede al otro tomarle su morir" [Keiner kann dem Anderen sein Sterben abnehmen] (SuZ: 240).

Por último, es menester enfatizar que el tratamiento del ser-para(vuelto-a)la muerte produce una potenciación sobre unos de los caracteres existenciales

\footnotetext{
${ }^{17}$ Conviene no olvidar que, si el Dasein es lo que hace y/o ocupa, también es lo que comparte.
} 
vertidos ya en el $\$ 9$, el cual, de alguna manera, recogía la singularidad ontológica del Dasein: el "ser-en-cada-caso-mío" [Jemeinigkeit] (SuZ: 42 y 240), en tanto estructura existencial que no solo recalca el carácter indeleble, "singularizante" e "irremplazable" del fenómeno del morir, siempre ya en relación con el Dasein, sino la constatación experiencial de que este "ser-en-cada-caso-mío" pertenece al modo de ser de tal ente, siendo que existir ya comporta el hecho de sostener y asumir, ora de modo impropio, ora de modo propio y resuelto, nuestro fin(al), como algo que nos va e implica de modo radical y lacerante. El ser-para(vueltoa)-la-muerte ha hecho acreditable la constitución de este Dasein como ser-encada-caso-mío.

\subsection{El todavía-no}

El ser-para(vuelto-a)-la-muerte tiene que incorporar, como la cara y la cruz de una moneda, el momento del aparecer antagónico de la falta o lo "faltante" [Ausstand]. Desde este aspecto, es posible aprehender el fenómeno de la muerte como algo que, mientras existimos, no es solo lo que nos impediría, de una forma terminal, ser, sino que constituye lo que nos quedaría por ser/existir (SuZ: 241). A partir de entonces, es menester realizar un análisis sobre la noción de falta de cara a ponerla, en último término, en relación con la noción ya abierta y pensada de "fin(al)". Por lo que parece, esa falta es comprendida de modo cotidiano bajo la manera de la suma y el resto, es decir, en tanto lo que falta de ser en conjunción a una estructura total, a un todo. De este modo es posible pensar la relación que hubiera entre las partes y el todo. Heidegger deja muy en claro la incongruencia temática de esta manera de entender la falta a la hora de abordar la elucidación del fenómeno de la muerte. En efecto, el modo como las partes "llegan a ser" [Werden], en su devenir, el todo, dista abismalmente de la manera en la que el Dasein muere, es su fin(al) (SuZ: 243). Bajo ningún parámetro la muerte puede significar para el existente un "finalizar" [Enden] o una "consumación" [Vollendung]. En este constreñido horizonte, mediante el cual ha salido a luz la noción complementaria a la falta, o sea: el fin(al), Heidegger realiza un ejemplo sobre la maduración del fruto, aparentemente no inquietante y de apariencia ascética. ¿Por qué Heidegger, en su análisis fenomenológico, elige, a fin de pensar el finalizar del Dasein, la comparación con la maduración de un 
fruto y no, más bien, con su caducidad o acabamiento? ${ }^{18} \mathrm{Y}$ esto a pesar, como se puede experimentar, que el Dasein, en la mayoría de los casos, muere, inmaduro e infecundo: el Dasein es su "todavía-no" [Noch-nicht] con igual "originariedad" por la que es su fin(al) (SuZ: 245 ss.).

El todavía-no, por tanto, va a constituir el principal filtro diferenciador por el que consideraciones del tipo categorial no puedan ser susceptible de aplicación, a fin de captar y tematizar la singularidad del modo de ser del Dasein. Mientras el todavía-no irrumpa como correlato del ser-el-mundo, el ser-para(vuelto-a-)la-muerte seguirá distando de la mera muerte, comprendida como fenecer.

\section{Ser-para(vuelto-a)-la-muerte: una naciente mismidad}

A continuación se va a desarrollar, a saber, estos diferentes horizontes meditativos: primero, se explicará el modo en que interrelacionan ser-total, serpara(vuelto-a)-la-muerte y cuidado; segundo, se dará cuenta de la incardinación del existenciario sobre la muerte en el modo por el que el Dasein es el "unomismo" [man-selbst], o sea: la cotidianidad; tercero, se intentará mostrar porqué la mismidad es un fenómeno eminente a fin de mostrar, explicar y/o tematizar la propiedad del Dasein, ya incluida, de alguna manera, en el ser-para(vueltoa)-la-muerte.

\subsection{Ser-para(vuelto-)-la-muerte, ser-total y cuidado}

El ser-para(vuelto-a)-la-muerte es un modo de relación del Dasein con su propio ser, el cual es siempre ya cuidado. En términos más concretos, tal afirmación manifiesta la necesidad de la relación del Dasein con su fin(al) desde 3 momentos temporales, cual éxtasis, a saber: "el anticiparse a sî" [das Sich-vorweg], "el ser-ya-en" [das Schon-sein in] y "el ser-junto-a" [das Sein-bei], como se sabe

18 Por motivos de extensión, no podemos desarrollar tal temática. Recomendamos la lectura de A. Vigo (2016: 237). 
correlatos de los momentos estructurales denominados por orden de sucesión: "existencia" [Existenz], "facticidad" [Faktizität] y "caída" [Verfallen].

\subsubsection{La anticipación}

La referencia de la anticipación significa que el Dasein, en tanto poder-ser, se ve obligado a existir en las modalidades del todavía-no y la falta, integrando a través de tales modalidades la posibilidad fáctica del fin(al), es decir, la muerte. Esto hace que tal fin(al) aparezca caracterizado en tanto "inminente" [Bevorstand]. Como ya se ha dejado ver, una caracterización de este tipo no es inmune a interpretaciones niveladoras, las cuales retraducen las formas existenciales a plenos objetos subsistentes, basados en la quiddidad del ente. De suerte que la temporalidad del Dasein [Zeitlichkeit] no se deje aprehender por procesiones categoriales de tal calado. La temporalidad es un fenómeno refractario siempre ya ante su concreción específicamente objetiva, de tal manera que lo que diferencia al ser-para(vuelto-a)-la-muerte de las diferentes tipologías, digamos, reductoras del fenómeno, es la puesta en juego de una posibilidad, ya acreditada por la anticipación, que pertenece al Dasein mismo, por la cual este ente, siempre ya, tiene que hacerse cargo, por la sencilla razón de que tal posibilidad constituye su "ser" (existencia). La inminencia de la muerte, aunque por el momento no ubicada en su posibilidad más propia, deja reflejar un aspecto existencial propicio, a fin de traslucir la peculiaridad existencial del Dasein, pues el no poder-ser-más-ahí, relativo a la muerte, de carácter inminente, coloca a este ente ante una cierta y vaga constatación de su más propio poder-ser, o sea, en una posibilidad de orden existencial no subsumida por el carácter atractivo y de sustracción del mundo, en tanto correlato de la llamada refracción ontológica, sino como un poder-ser de alguna manera absuelto de las referencias hermenéuticas de la consolidación de mundo ${ }^{19}$. La afirmación tremebunda de que la muerte es "la posibilidad de la llana imposibilidad de la existencia" [die Möglichkeit der schlechthinnigen Daseinsunmöglichkeit] cobra ahora todo su sentido, revelándose de este modo el morir

19 Esta absolución del mecanismo de ilación hermenéutica del mundo, en tanto absorción en el ente intramundano, no significa que, en el momento disruptivo insinuado en la anticipación del ser-para(vuelto-a)-la-muerte, el Dasein deje de ser-en-el-mundo; antes al contrario, es en este momento cuando el ser-en-el-mundo se muestra en su carácter esencial como posibilidad de una posibilidad. Hemos desarrollado esta temática en Garrido-Periñán, 2019b: 887-911. 
que acompaña al Dasein como la posibilidad "más propia” [eigenst], "irreferible" [unbezüglich] e "insuperable" [äußerst] (SuZ: 250).

Por tanto, el ser-para(vuelto-a)-la-muerte ha posibilitado la concreción de lo que hasta el momento era una constatación vaga e infértil: el cuidado como totalidad del ser del Dasein, por un lado, y el anticiparse como un momento co-originario de la transparencia del carácter proyectivo y "futurizante" de la existencia, por otro, siendo que tal existenciario sobre la muerte es la vía de concretización fenoménica de la anticipación misma.

\subsubsection{El ser-ya-en}

El existenciario, constituido como otro momento co-originario del cuidado, relativo al "ser-ya-en", tendrá que ver con la facticidad. En relación con la muerte, la facticidad significa que el morir no adviene a posteriori de la existencia, sino que pertenece a la estructura existencial de lo que siempre ya ha existido. Tal es así que, cuando Heidegger desarrolla la condiciones de la "aperturidad" [Erschlossenheit] del ser-en, en el momento de explicitación de la "disposición afectiva" [Befindlichkeit] (SuZ: 134-140), define a ésta como una articulación comprensiva de carácter no-apofántico, marcada por la impronta de la facticidad, entendida como mero "encontrarse" [sich-befinden], que luego será, de manera lacerante y sufriente, manifestada en el estado de apertura pleno: la "angustia" [Angst] (SuZ: 194-191). Esta última consideración es harto importante para comprender la dinámica de la posibilidad inherente al ser del Dasein, de tal manera que tal dinámica no es solo "futurizante" ni proyectiva, sino retro-activa-proyectiva: hay una relación con una posibilidad, que se hace eminente con el fenómeno del morir, por la cual estamos vueltos hacia nuestro e "irrespectivo" fin(al) (SuZ: 250 ss.). Todas las características que se puedan enmarcar a través del fenómeno de la angustia, dentro de la experiencia humana, como puede ser las modalidades de inquietud, intranquilidad, desazón, etc., anexadas a tal grado de afección, tienen su respuesta en virtud de la irrupción de la muerte como momento indisponible, que no se controla a voluntad. La forma mediante la cual el Dasein se relaciona con su facticidad, en mediación con la muerte, y además sabe de ella, constituye el primer, por cuanto originario, conocimiento, más allá de sus posibles nivelaciones y/o desfiguraciones proyectadas por la cotidianidad, la cual sirve como base para alcanzar su acreditación vía experiencia y, por ende, desde el lado de la situación hermenéutica, permitir la demarcación de posibles críticas de acusación 
sobre el carácter artificial y fantasmagórico del análisis adoptado. Para resumir, si la facticidad fuera una determinación de orden de lo heterónomo, no tendría porqué afectarnos el hecho bruto de la muerte, justamente, al contrario, es por mor de que la facticidad es siempre, de alguna manera, asumida por el Dasein, por la que esta misma facticidad, entendida como una estructura de lo ya-sido y, por tanto, de lo que pertenece a lo heredado/cultural/pasado, nos va de alguna manera, nos concierne en nuestro ser, y tenemos que soportarla, asumirla.

En esta manera de "irnos" y afectarnos por lo aparentemente heterónomo de la facticidad, indica ya la presuposición de las modalidades relativas a la impropiedad, la indiferencia modal y la propiedad ${ }^{20}$ (SuZ: 232 ss.).

\subsubsection{El ser-junto-a}

En el momento estructural relativo al ser-junto-a y desde su correlato: la caída, se produce una articulación temática, análoga al momento de la interpretación sobre la comprensión afectivamente dispuesta desarrollada en los $\$ \$$ 29-31. De ahí que lo abierto por la modalidad respectiva al ser-junto-a, pueda revestir un saldo positivo sobre el análisis desarrollado. De lo contrario, si el Dasein estuviera siempre ya alienado en interpretaciones de carácter cósico, la posibilidad de desarrollo de la pregunta filosófica por antonomasia, aquella que se retrotrae a la modalidad perteneciente a los existenciarios, su restitución en un elemento de "sentido", no podría ser llevada a cabo en su posibilidad más plena (SuZ: 251). En este sentido, la caída no es solo el horizonte intencional por el cual el Dasein vive encadenado a horizontes significativos de carácter nivelador, sino el suelo nutricio donde se puede ejercer la posibilidad de una comprensión en propiedad del Dasein de sí-mismo.

20 Muy interesante es la mención de la modalidad de concreción existencial denominada "indiferencia" [modale Indifferenz]. Por diversos motivos, tanto de forma como de contenido, no abstenemos de desarrollar una interpretación de tal modo de ser basado en la indiferencia, a fin de centrarnos en el binomio impropiedad-propiedad. Valga esta indicación como suficiente: la indiferencia modal sería un modo derivado de la impropiedad, no de la propiedad, porque, en todo caso, un Dasein indiferente es aquel que ve socavado y obturado un momento estructural de su apertura: la "disposición afectiva" [Befindlichkeit]. 
En virtud de lo último expresado, quedaría mostrado no solo el porqué el cuidado es el título ontológico que recoge la totalidad estructural del ser del Dasein, sino que el ser-para(vuelto-a)-la-muerte representaría su condición posibilitadora. El cuidado, entonces, se revela como todo estructural del Dasein mediante la irrupción del ser-para(vuelto-a)-la-muerte y, por otro lado, el serpara(vuelto-a)-la-muerte quedaría integrado, en relación con el Dasein por mediación del cuidado, en calidad de estructura temporal posibilitadora.

\subsection{El uno-mismo no es la mismidad del Dasein}

La cotidianidad no es más que un desarrollo explícito del modo por el cual el Dasein es el uno-mismo. Esto significa, en términos formales, que la cotidianidad del término medio, promovida por la consolidación intencional del unomismo, provee al Dasein de un estado de apertura afectivamente comprensivo, a través del cual este ente cae, se topa, con una comprensión dada del mundo, de las cosas que le rodean e incluso de una manera de entender la alteridad. Pero, por lo demás y hasta el momento, lo manifestado ya fue explicado con cierta demora por Heidegger, en el tratamiento de las formas de apertura del "ser-en" [In-sein] (SuZ: 130-180) ¿Por qué, ahora, repetir lo mismo? He aquí la importancia del fenómeno del ser-para(vuelto-a)-la-muerte, pues va a servir de fundamento cuasi-genético de la cotidianidad, en la medida en que ésta queda englobada como una forma cadente de huida y cerrazón para con este existenciario: siempre ya la cotidianidad va a erigirse como un mecanismo de reacción ante la posibilidad eminente dejada atrás por el saber no-apofántico, articulado en la disposición afectiva, de la facticidad emanada del ser-para(vuelto-a)-la-muerte. Por esta razón, Heidegger elabora toda una descripción de carácter hermenéutico donde la cotidianidad adquiere formas niveladoras, alienantes, de efecto de descarga, no digamos también de resultados analgésicos para con la verdad irrecusable brindada por el saber de la muerte: el poder-ser es un factum que ha de ser asumido en cada caso por cada Dasein, porque, entre tanto, forma parte de nuestra constitución ontológica inexcusable. Ante este descubrimiento, sobre todo si pensamos que el uno-mismo es la consolidación, en términos pregnantes, de esta dinámica alienante denominada caída, podemos entrever ya que la forma genuina, por cuanto ontológica, de ser sí-mismo, o sea de la mismidad, no es la establecida por este uno-mismo, por la razón de que el uno-mismo está determinado como reacción a este saber de la muerte, (pre-)sentido, comprendido en la posibilidad del Dasein. 


\section{La mismidad del Dasein: condición necesaria y suficiente}

Esta mismidad, hasta el momento, solo ha sido supuesta tangencialmente en el análisis ejercido. En efecto, hasta el momento se han llevado a cabo 2 posibilidades del análisis fenomenológico relativo al morir: a) se ha obtenido un concepto existenciario pleno sobre tal fenómeno; b) se ha abierto un horizonte de su posible concreción y advenimiento en tanto estado de propiedad del Dasein. En todo caso, lo que no se ha realizado es una interpretación, de carácter ejecutivo, que dé cuenta del tránsito desde la impropiedad a la propiedad, de cara a mostrar de qué modo la mismidad es un existenciario que constituye una condición necesaria y suficiente de tal estado de propiedad. De lo que se tratará en adelante es de intentar desvelar formas existenciales transidas por el carácter proyectivo-anticipativo ya avistado en el dominio hermenéutico y referencial relativo al ser-para(vuelto-a)-la-muerte.

\subsection{La posibilidad de una posibilidad}

¿Cómo existe el Dasein en su más propia posibilidad? ¿cómo es posible un comportarse, en propiedad, con respecto a su fin(al)? En este sentido, Heidegger habla de la posibilidad de abrir un "esbozo existenciario" [existenzialer Entwurf] (SuZ: 260-267) sobre la posibilidad de que el Dasein, una vez habiéndose "experienciado" en su posibilidad más extrema e "irreferible", pueda comportarse en homologación a su poder-ser. Esta pretensión es, a nuestro juicio, más radical que la petición de búsqueda y tematización del fenómeno de la muerte como un fenómeno relativo a lo abierto por el ser-para(vuelto-a)-la-muerte. Antes bien, implicaría la posibilidad de ejercer una comprensión en el mismo acto de la ejecución que conforma la existencia. En otros términos: Heidegger intuye que el Dasein solo puede ser en propiedad si logra abrir, a modo de esbozo, un conocimiento expresado como ejecución-comprensiva, el cual presenta, en referencia indeleble al Dasein, el carácter de una posibilidad, por oposición al carácter relativo a lo Vorhandenheit. De este modo, un poco más tarde, en relación con la ejecución de esta comprensión existencial, Heidegger versará sobre la "conciencia práctica" [Gewissen] (SuZ: 270-280), a fin de poner en claro la posibilidad de un saber no-teórico, capaz de llevar a término el tránsito entre impropiedad y propiedad. Sin embargo, en nuestra opinión, tal intento, aunque suficiente, no adquiere la modalidad de necesario, justamente bajo la finalidad 
de dar cuenta de la misma posibilidad ontológica, por la que el Dasein es lo que es en relación con su fin(al) ¿Por qué manifestamos semejante cosa? Hay que pensar, ahora, sobre la "mismidad" [Selbstheit] del Dasein, la cual juega un rol que excede a su posible determinación como petición de principio de la pregunta por la propiedad. Además, a nuestro parecer, la mismidad se incardina como garante de la misma posibilidad en tanto posibilidad -de lo que trata la "resolución precursora" [vorlaufende Entschlossenheit] (SuZ: 309)-. Precisamente, la tarea, ardua y esquiva, que se propone Heidegger con la articulación aprehensora del modo de ser de la propiedad del Dasein, radica en la ejecución-comprensiva de una posibilidad, que es el Dasein en su tendencia al fin(al), en tanto poder-ser, configurando y preservando el carácter de tal posibilidad, aunque ésta se vea concretizada y, de algún modo, susceptible de presentar el carácter de lo cósico, es decir, muy a pesar de la tendencia -de ahí la caída- mediante la cual el Dasein convierte su nudo poder-ser, radical y lacerante, en formas comprensivas-afectivas evidentemente concretas, bajo el carácter de uso, en el mundo-entorno, o englobadas en el aspecto de lo "ante los ojos" [vorhanden], por ejemplo. Tales formas son degradaciones de tal posibilidad por la que el Dasein es incapaz no solo de tematizar su posibilidad radical, sino de conservar tal posibilidad, entrañable con respecto a su constitución existencial, a través de una comprensión de carácter ejecutivo. El poder-ser, que se ha dejado ver a través del ser-para(vuelto-a)-la muerte, en su articulación como aprehensión de la totalidad del ser del Dasein, ha de entenderse como esa constatación de la posibilidad como posibilidad, o sea, como una posibilidad, inherente al modo de ser del Dasein, que presenta un carácter refractario para sus posibles "modalizaciones" ónticas, presentando al Dasein, su originario poder-ser, en divorcio con las "modalizaciones" respectivas a su concretización, en el mundo de los otros o en el mundo-entorno. Sale a relucir así un saber de una posibilidad, que es el Dasein mismo, abismal, desmesurada, la cual, como se ha manifestado ya, es definida por Heidegger como una radical posibilidad de la imposibilidad del poder-ser del Dasein. De ahí que al Dasein solo le quede "adelantarse a la posibilidad" [Vorlaufen in die Möglichkeit] (SuZ: 261262), posibilidad que es suya, siempre y en cada caso.

Pues bien, si no nos sintiéramos concernidos por esta posibilidad existencial ¿habría alguna motivación para que nos comportemos conforme a la propiedad de nuestra existencia y no, más bien, que viviéramos, siempre ya, en el modo de la impropiedad? En nuestra opinión, es aquí donde debe ser pensada la mismidad del Dasein como un modo de apertura de este mismo Dasein con respecto a sí, o sea, como un fenómeno de auto-referencialidad sobre todo modo de comportarse en-el-mundo. En relación con esto, el ser para(vuelto-a)-la muerte ya dejó 
constancia de esta posibilidad sobre la mismidad, aunque de modo latente: la muerte quedó caracterizada existencialmente como el fenómeno: a) "más propio" [eigenst], b) "irreferible" [unbezüglich], c) "insuperable" [äußerst], d) "cierto" [gewiß] e) "incierto/indeterminado" [ungewißlunbestimmt]. A través del fenómeno autorreferencial denominado mismidad, empleado por Heidegger de modo tangencial mediante la expresión de un "sí-mismo-propio" [eigene Selbst] (SuZ: 262 ss.), podrán comprenderse rectamente tales caracterizaciones.

\section{a) La muerte como fenómeno más propio.}

Que el ser-para(vuelto-a)-la-muerte se constituye como el más propio poderser del Dasein, tiene que ser pensando en tanto correlato de la anticipación promovida por el cuidado y en confrontación con la manera en la que se cristalizan las disposiciones conformadas por la cotidianidad bajo la signatura del uno-mismo. Esto quiere decir que la más propia posibilidad, constituyente del ser del Dasein, es esbozada a contracorriente de las formas de comprender las posibilidades donadas por el uno-mismo, no lo olvidemos, determinado por Heidegger como una forma niveladora y auto-delegatoria de existir (SuZ: 126-130) ¿Qué es lo que se nivela y se delega? Justamente, la imprecación a ser conforme a la más propia posibilidad en relación con nuestro fin(al). La forma, comprensivaejecutiva, de ser la más propia posibilidad, por oposición a la forma uno-mismo, conllevaría ser con respecto al sí-mismo del Dasein. Por tanto, el Dasein, cuando se abre por vía de la anticipación su más propio poder-ser, está siendo lo que es, es decir, está llevado a cabo una forma eminente de mismidad, la única posible.

\section{b) La muerte como irreferible.}

La "irreferibilidad" ha de entenderse como una contraparte en la determinación del más propio ser-posible del Dasein, manifestando, en cambio, la necesidad de hacerse cargo, de manera individual, de tal poder-ser. "Irreferible" es la relación hacia nuestro fin(al) no solo porque nos obligue a su asunción dentro de un proyecto hermenéutico de vida, que apuntará a cada existente, como "individuación/singularización” [Vereinzelung], sino porque la muerte, como fenómeno existencial, romperá con cualquier atisbo de ligazón referencial con el mundo compartido y el mundo-entorno, provocando un cisma, de aspecto colosal, en el seno de la existencia. Esto, por lo demás, quiere manifestar que lo que se le abre al Dasein, siendo este ente un modo eminente de apertura, constituido en el "ahî" [Da] del ser, y como ser-descubridor del ente, es su más propia posibilidad; es decir, a partir de la caracterización como "irreferible", el Dasein se enfrenta con 
su sí-mismo, se abre para sí-mismo lo que es (SuZ: 263 ss.), obviamente no como desligado de la dinámica hermenéutica provista en su constitución existencial como ser-en-el-mundo, sino a la manera de la anticipación, en virtud de la cual el Dasein, siendo en-el-mundo, es siempre ya para sí-mismo su más "irreferible" posibilidad, en el "ser-en-cada-caso-mío" [Jemeinigkeit].

\section{c) La muerte como insuperable.}

El Dasein no puede colocarse fuera de su propia e "irreferible" relación con su fin(al), siendo que, cual observador imparcial, pudiera tematizar y comprender tal fenómeno externamente. La radicalidad del poder-ser del Dasein es tan excesiva que su supresión, por vía de su "superación" [Überwindung], a saber, epistemológica, significaría su misma aniquilación. En efecto, todas las modalidades, a través de las cuales se lleva a cabo una determinación del sí-mismo propio del Dasein, ora como ego cogito, ora como sujeto-trascendental, etc., han de ser entendidas no solo como formas niveladoras y desfiguradoras de esta mismidad, a la que parece indicar el ser-para(vuelto-a)-la-muerte, sino, antes bien, como determinaciones aniquiladoras de que el Dasein sea lo que realmente "es". Además, por si esto no fuera poco, el carácter de insuperable de la muerte obliga al Dasein a pensarse, a través de su anticipación existencial, como un ser finito, pues la pregunta sobre el "más allá" [Jenseits] de la muerte no tendría ningún sentido, al considerar tal pregunta, desde la perspectiva del "más acá" [Diesseits], algo extemporáneo e inaudito, de imposible consecución fenomenológica.

\section{d) La muerte es cierta.}

La muerte no es un punctum en el tiempo, el cual acontecerá de modo cierto, en tanto destino, e incierto y/o indeterminado, en relación con su consumación. Tampoco el carácter de certeza, inherente a la muerte, debe ser entendido al modo de una correspondencia veritativa con la cosa, pues la muerte, en términos existenciales, no presenta el carácter de lo cósico (SuZ: 264 ss.). En cambio, el carácter de cierto adviene por mor de la relación "irreferible” que el Dasein mantiene con su propio fin(al), pero, digamos, del lado, por así decir, noemático-objetivo del término: la certeza de la muerte es un rendimiento del estado de apertura de tal muerte en tanto posibilidad conectada con la modalidad del sí-mismo propio y/o mismidad del Dasein. Así, de esta manera, la certeza, digamos, de carácter ontológico, debe ser comprendida como una "posibilitación anticipadora" [vorlaufende Ermöglichkeit], por la cual la muerte existencial es incorporada, siempre ya, a las dinámicas producidas en el "estado de apertura" 
[Erschlossenheit], que el Dasein siempre comporta, en tanto ser-en-el-mundo. Por esta razón, la certeza de la muerte-existencial puede ejercerse como cierta, en la medida que ella remite al estado de apertura del Dasein, el cual ha de entenderse como modalidad en la que este ente es su sí-mismo más propio.

\section{e) La muerte es incierta e indeterminada.}

A este respecto, Heidegger habla de "la indeterminación de la certeza" [die Unbestimmtheit der Gewißheit] (SuZ: 265). Prima facie, esta afirmación, como es por lo demás usual en Heidegger, puede mover a la confusión. De nuevo, si se tienen en cuenta las sujeciones metódicas recogidas en el libro de 1927, podrá comprobarse la férrea relación consecuente manifestada en tal afirmación, donde se relaciona certeza e indeterminación, ya que, además de extender la determinación de la comprensión como un acto siempre afectivamente abierto, se puede colegir de qué manera el Dasein se relaciona con su fin(al) y, luego, de qué modo es abierto y/o comprendido este fin(al) como cierto, implica una disposición afectiva ejercida por el Dasein, ya que es su mismo ser el que queda en juego, vivido como una constante "amenaza" [Bedrohung], en la que no solo sale a escena la posibilidad radical de dejar de ser o existir, sino la constatación de que aquello a lo que tendemos como fin(al) no es una cosa, un objeto, susceptible de objetivación e identificación lógica. Es esta resistencia a la definición categorial la que explica el porqué se puede conjugar certeza e indeterminación en el ser-para(vuelto-a)-lamuerte, pues, siempre ya, la posibilidad radical de la muerte se revela como una posibilidad radical de nuestro existir. No es baladí, por lo demás, que la calificación de indeterminada e incierta ejercida sobre el existenciario ser-para(vuelto-a)-lamuerte, nos ponga en relación con un aspecto del sí-mismo del Dasein que no debe ser olvidado: si el Dasein es, siempre ya, su radical (im)posibilidad, acrecentada y abierta en el saber de la muerte, esto significa que la mismidad del Dasein ha de estar en homologación con los caracteres existenciales expuestos por tal posibilidad. De otro modo: la indeterminación del saber de la muerte, el cual resurge porque la posibilidad abierta afectivamente presenta el modo de la posibilidad radical -0 sea, no objetual-, es indeterminada en sus términos, precisamente, por mor del Dasein, un ente, como se ha reiterado ya, provisto de características formales-existenciales, el tener-que-ser y el ser-en-cada-caso-mío, ambas resistentes a su objetivación. De tal manera que la indeterminación de la muerte es sostenible en la medida en que tal posibilidad ante la muerte se vea incorporada en la apertura a la comprensión que el Dasein siempre es, o sea, en la medida en que pueda ser abierta y sostenida por el propio Dasein en tanto sí-mismo. 


\section{Conclusiones}

La hipótesis de partida, que ha servido de urdimbre en el análisis fenomenológico llevado a cabo, radicó en que la posibilidad más propia, si no se ve conformada como reflejo del mundo, debe sacar a la luz lo más idiosincrático del Dasein, aquello que hemos llamado mismidad, en tanto correlato del denominado existenciario "anticiparse a la posibilidad" [Vorlaufen in die Möglichkeit] (SuZ: 299). Esta mismidad se entendió como un modo propio de ser, por el que el Dasein no es confundido con el mundo-entorno y el mundo-compartido, donde siempre le son abiertas disposiciones y/o horizontes afectivamente comprendidos. La mismidad se constituyó no solo como una posibilidad, sino como una posibilidad ejecutiva que, en su realización existencial, "a cada instante" [Jeweiligkeit], debe anticiparse y preservarse en su carácter, o sea, como posibilidad emanada y en concordancia con el peculiar modo del ser del Dasein. La mismidad no es solamente el rendimiento fenomenológico de un estado de apertura con respecto al Dasein mismo, sino el motor que mueve al mismo Dasein a ser, existir, buscar y anhelar la propiedad, una propiedad siempre debilitada por la consolidación de un mundo hermenéuticamente articulado.

Al Prof. Pepe Ordóñez, en señal de admiración y amistad, ambos circundados por el saber de la muerte.

\section{Bibliografía}

Arendt, Hannah (1998). The Human Condition, Chicago: The University of Chicago Press.

CaYgill, Howard (2000). A Kant Dictionary, Oxford-Massachusetts: Blackwell.

Edwards, Paul (1979). Heidegger and Death. A Critical Evaluation, Illinois: Open Court Pub.

Gadamer, Hans-Georg (1993). Wahrheit und Methode. Gesammelte Werke, Band 2, Tübingen: Mohr Siebeck. 
Garrido-Periñán, Juan José (2019a). "La pregunta por el quién del ser-con: Heidegger en su Ser y Tiempo". Anales del Seminario de Historia de la Filosofía 36/1, pp. 175200.

(2019b). "La aportación no-apofántica de la disposición afectiva y la mismidad del Dasein: análisis fenomenológico a partir del momento estructural ser-en". Pensamiento: Revista de Investigación e Información filosófica 75/285, pp. 887-911.

(2019c). "Vinculabilidad entre cuidado y mismidad en los $\$ \$ 39-42$ de Ser y Tiempo". Alpha: Revista de Artes, Letras y Filosofía 49, pp. 159-175.

Heidegger, Martin (2015). Anmerkungen I-V (Schwarze Hefte 1939-1941), IV Abteilung, Band 97, Frankfurt a.M., Vittorio Klostermann.

- (2013). Zum Ereignis (1941/42), III Abteilung, Band 73. Frankfurt a.M.: Vittorio Klostermann.

- (2006). Einführung in die phänomenologische, Forschung, II. Abteilung, Band 17. Frankfurt a.M.: Vittorio Klostermann.

- (2002). Sein und Zeit, Tübingen: Max Niemeyer.

- (1995). Phänomenologie des religiösen Lebens, II. Abteilung, Band 60, Frankfurt a.M.: Vittorio Klostermann.

- (1992). Platon: Sophistes. II. Abteilung, Band 19, Frankfurt a.M.: Vittorio Klostermann.

- (1989). Beiträge zur Philosophie (Vom Ereignis), III. Abteilung, Band 65, Frankfurt a.M.: Vittorio Klostermann.

- (1988). Ontologie (Hermeneutik der Factizität), II Abteilung, Band 63. Frankfurt a.M.: Vittorio Klostermann.

- (1983). Einführung in die Metaphysik (Sommersemester 1935), II Abteilung, Band 40, Frankfurt a.M.: Vittorio Klostermann.

- (1981). Die Frage nach dem Ding. Zu Kants Lehre von den transzendentalen Grundsätzen, II. Abteilung, Band 41, Frankfurt a.M.: Vittorio Klostermann.

- (1979). Prolegomena zur Geschichte des Zeitbegriffs (Sommersemester 1924), II. Abteilung, Band 20, Frankfurt a.M.: Vittorio Klostermann.

- (1976). Wegmarken, Gesamtausgabe, I. Abteilung, Band 9,Frankfurt a.M.: Vittorio Klostermann.

- (1975). Die Grundprobleme der Phänomenologie, II Abteilung, Band 24, Frankfurt a.M.: Vittorio Klostermann.

Jaspers, Karl (1990). Psychologie der Weltanschauugen, Berlin: Springer.

- (1932). Philosophie, Band 2: Existenzerhellung, Berlin: Springer. 
Kant, Immanuel (2005). Critica de la razón pura, Madrid: Taurus.

- (1993). Opus postumum, New York: Cambridge University Press.

Lehmann, Karl (1938). Der Tod bei Heidegger und Jaspers, Heidelberg: Evangelischer Verlag Jakob Comtesse.

Lütkehaus, Ludger (2006). Natalität. Philosophie der Geburt, Kusterdingen: Die Graue Edition.

Vigo, Alejandro (2016). "El posible ser total del Dasein y el ser para (vuelto a) la muerte (\$\$. 45-53)”, en R. Rodríguez (ed.), Ser y Tiempo de Martin Heidegger. Un comentario fenomenológico, Madrid: Tecnos, pp. 219-268.

- (2014). Arqueología y Aleteiología. Estudios heideggerianos, Berlin: Logos Verlag.

Este trabajo se encuentra bajo una licencia de Creative Commons Reconocimiento-

NoComercial-SinObraDerivada 4.0 